\title{
Review
}

\section{Immune-Based Therapeutic Strategies for Acute Myeloid Leukemia}

\author{
Matthias Böhme ${ }^{1}$ and Sabine Kayser ${ }^{1,2, *}$ \\ 1 Medical Clinic and Policlinic I, Hematology and Cellular Therapy, University Hospital Leipzig, \\ 04103 Leipzig, Germany; matthias.boehme@medizin.uni-leipzig.de \\ 2 NCT Trial Center, National Center of Tumor Diseases, German Cancer Research Center (DKFZ), \\ 69120 Heidelberg, Germany \\ * Correspondence: s.kayser@dkfz-heidelberg.de; Tel.: +49-341-9713050; Fax: +49-341-9713059
}

Citation: Böhme, M.; Kayser, S. Immune-Based Therapeutic

Strategies for Acute Myeloid

Leukemia. Cancers 2022, 14, 105.

https://doi.org/10.3390/

cancers14010105

Academic Editor: Christian Buske

Received: 20 November 2021

Accepted: 21 December 2021

Published: 27 December 2021

Publisher's Note: MDPI stays neutral with regard to jurisdictional claims in published maps and institutional affiliations.

Copyright: (c) 2021 by the authors. Licensee MDPI, Basel, Switzerland. This article is an open access article distributed under the terms and conditions of the Creative Commons Attribution (CC BY) license (https:/ / creativecommons.org/licenses/by/ $4.0 /)$.
Simple Summary: This review summarizes various therapeutic immune approaches representing their targets, the efficacy and toxicity in the treatment of acute myeloid leukemia. In particular, immune checkpoint inhibitors, bispecific T-cell engager antibodies and chimeric antigen receptor-Tcell approaches are highlighted.

\begin{abstract}
The development and design of immune-based strategies have become an increasingly important topic during the last few years in acute myeloid leukemia (AML), based on successful immunotherapies in solid cancer. The spectrum ranges from antibody drug conjugates, immune checkpoint inhibitors blocking programmed cell death protein 1 (PD1), cytotoxic T lymphocyte antigen 4 (CTLA4) or T cell immunoglobulin and mucin domain containing-3 (TIM3), to T-cell based monoclonal and bispecific T-cell engager antibodies, chimeric antigen receptor-T-cell (CAR$\mathrm{T})$ approaches and leukemia vaccines. Currently, there are many substances in development and multiple phase I/II studies are ongoing. These trials will help us to deepen our understanding of the pathogenesis of AML and facilitate the best immunotherapeutic strategy in AML. We discuss here the mode of action of immune-based therapies and provide an overview of the available data.
\end{abstract}

Keywords: acute myeloid leukemia; immunotherapy; bispecific and dual antigen receptor-targeting antibodies; chimeric antigen receptor T-cell therapies; T-cell immune checkpoint inhibitors

\section{Introduction}

Acute myeloid leukemia (AML) is characterized by medullary or peripheral presence of immature, undifferentiated blast cells. Per its definition, AML is characterized by $\geq 20 \%$ blast cells in the bone marrow or peripheral blood, and the infiltration of extramedullary tissues is also possible. The accumulation of various somatically acquired genetic changes in hematopoietic progenitor cells that alter normal mechanisms of self-renewal, proliferation, and differentiation leads to its genetic heterogeneity [1]. Currently, the following cytogenetic abnormalities are considered as AML-defining: $t(15 ; 17), t(8 ; 21)$ and inv(16)/t(16;16), irrespective of blast percentage [2].

AML is typically a disease of the elderly with a median age of 72 years at diagnosis and an incidence of 3-4 per 100,000 adults per year. Overall, outcome is poor with a 5 -year survival rate of $\sim 40 \%$, which is rapidly declining with increasing age at diagnosis. Outcome is influenced by multiple factors, both patient-dependent, such as pre-existing comorbidities, and disease-dependent, such as cytogenetics, molecular abnormalities and response to initial therapy. Nevertheless, $~ 50 \%$ of younger ( $\leq 60$ years) and about $80-90 \%$ of older patients relapse after achieving their first complete remission (CR). Despite intensive consolidation therapy, the majority of relapsed patients succumb to their disease [3,4].

Based on the recent risk stratification by genetics $[5,6]$, patients can be stratified into three distinct subgroups: favorable, intermediate and adverse risk, of which only the favorable risk group of patients may be cured by chemotherapy alone. For all other patients, only 
allogeneic hematopoietic stem cell transplant (allo-HSCT) remains a potentially curative treatment option.

Until recently, similar chemotherapeutic approaches were used for the majority of patients [7]. Due to the discovery of new genetic abnormalities in AML, treatment options have expanded over the last few decades and ten agents have recently been approved by the Food and Drug Administration (FDA) in the United States. In Europe, the European Medical Agency (EMA) approved eight new targeted agents as therapeutic approaches in AML [8].

Another promising therapeutic avenue has been opened relying on immune-based approaches.

The principal idea is that leukemic stem and blast cells express aberrant antigens, which differ from the immunophenotype of normal hematopoietic stem cells. Thus, they may represent a potential target of attack for the immune system, which can be directed towards the disease either by antibody drug conjugates (ADC) or T-cell-based strategies.

This review focusses on the available clinical data of immune-based strategies including monoclonal antibodies (mAb) and ADCs, as well as T-cell-based therapeutics, such as bispecific antibodies, immune checkpoint-based approaches and chimeric antigen receptor-T-cells (CAR-T cells). Figure 1 shows an overview of the presented immune-based therapeutic approaches in AML. Most of the drugs/approaches are currently being evaluated in early phase I/II-trials. Thus, clinical data might be preliminary with safety and efficacy evaluations ongoing. Nevertheless, the latest results presented recently on large, international meetings are included.

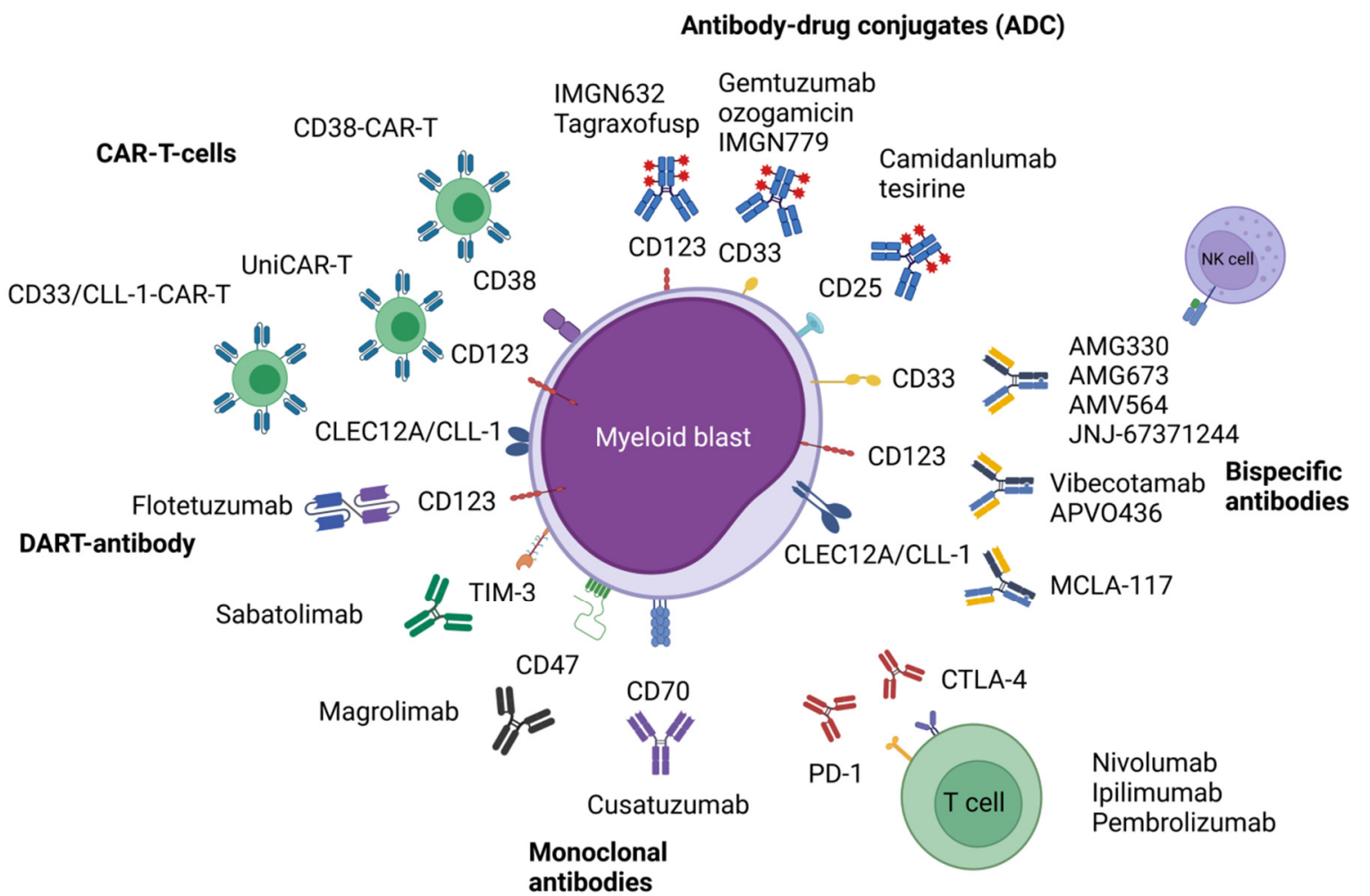

Figure 1. Illustrated overview of the presented immune-based therapeutic approaches in acute myeloid leukemia. Abbreviations: CAR-T, chimeric antigen receptor T-cell; CD, cluster of differentiation; CLEC12A, C-type lectin domain family 12 member A; CLL-1, C-type lectin-like molecule-1; CTLA-4, cytotoxic T-lymphocyte-associated protein 4; PD-1, programmed cell death protein 1; TIM-3, T-cell immunoglobulin and mucin-domain containing-3. Figure 1 was created with BioRender.com (accessed on 14 November 2021). 


\section{Modalities of Immune-Based Therapeutic Approaches}

The administration of mAb may use different pathways to interfere with leukemic stem cells and blast cells. Through recognition of specific antigens, growth signaling may be disturbed and immunological defense pathways activated, for instance complementmediated cytotoxicity (CDC), as well as antibody-dependent cell-mediated phagocytosis and antibody-dependent cellular cytotoxicity (ADCC). The release of antigens facilitated by such mechanisms leads to presentation by antigen-presenting cells and subsequent activation of CD8+ cytotoxic T-cells, which may directly attack and destroy leukemic cells [9].

However, through clonal evolution, all neoplastic cells have developed some degree of immune evasion, which may be based on different principles. Known examples comprise enhanced signaling of inhibitory immune checkpoints, such as programmed cell death protein 1 (PD1), cytotoxic T lymphocyte antigen 4 (CTLA4) and T cell immunoglobulin and mucin domain containing-3 (TIM3). In addition, inhibitory regulatory $\mathrm{T}$ cells $\left(\mathrm{T}_{\mathrm{reg}}\right)$ are promoted among others. The disruption of such signals by the use of immune checkpoint inhibitors is a promising approach in AML [9].

The upregulation of CD47, which is a "don't eat me" signal and strongly expressed in solid tumors and myeloid malignancies, results in inhibition of phagocytosis by macrophages and, thus, represents another approach of tumor immune evasion $[10,11]$. In preclinical models of AML and myelodysplastic syndromes (MDS), it could be demonstrated that the blocking of CD47 enhances antitumor response [12,13] and that the anti-CD47 antibodies stimulate ADCP, promoting priming and memory response of CD8 T cells [14].

Another mode of targeting leukemic cells consists of ADCs, which combine a cytotoxic agent chemically linked to a $\mathrm{mAb}$, thus using a directional way of delivering conventional chemotherapy. By binding to its ligand, the ADC is internalized by the target cell and releases its payload, resulting in cell death of the leukemic cell [9].

A further therapeutic modality consists of bispecific antibodies, which comprise two or more antigen-binding sites in a single antibody construct. One site recognizes a specific antigen on the leukemic cell, whereas the other binds to the effector T cell domain CD3 $\varepsilon$, thus allowing for immune cell activation independently of conventional major histocompatibility complex (MHC). The concept of bispecific antibodies allows for different constructs, such as bispecific T cell engagers (BiTEs) or dual-affinity retargeting antibodies (DART ${ }^{\circledR}$ ) [15]. The latter are described as two variable antigen-specific domains connected to two polypeptide chains, which are in turn linked covalently and non-covalently, improving the stability and crosslinking abilities of similar constructs.

A similar, yet different, therapeutic path lies in the use of CAR-T cells and analogous concepts. Despite their success in the treatment of lymphatic diseases, such as non-Hodgkin lymphoma and acute lymphoblastic leukemia (ALL) [16], current CAR-T approaches had only limited efficacy in AML due to the lack of suitable targets and a hostile immune microenvironment. Therefore, other ideas have been developed, i.e., the use of natural killer cells (CAR-NK), the application of T cell-receptor (TCR)-modified T cells and modular approaches to accommodate for safety concerns, such as the UniCAR system. In addition, vaccinations against leukemic antigens are currently being studied in clinical trials. Table 1 gives an overview of the different immune-based strategies currently being explored in clinical trials. 
Table 1. Overview of the presented immune-based therapeutic approaches in acute myeloid leukemia currently under clinical investigation.

\begin{tabular}{|c|c|c|c|c|c|c|c|}
\hline Target & Drug Name & Drug Type & Therapy & Indication & $\begin{array}{c}\text { Developmental } \\
\text { Stage }\end{array}$ & $\begin{array}{l}\text { Available } \\
\text { Results }\end{array}$ & $\begin{array}{c}\text { NCT } \\
\text { Number/ } \\
\text { Reference }\end{array}$ \\
\hline \multirow{7}{*}{ CD33 } & $\begin{array}{l}\text { Gemtuzumab } \\
\text { ozogamicin }\end{array}$ & $\mathrm{ADC}$ & $\begin{array}{c}\text { Intensive } \\
\text { chemotherapy }\end{array}$ & $\begin{array}{l}\text { de novo } \\
\text { AML }\end{array}$ & $\begin{array}{l}\text { EMA and FDA } \\
\text { approved } \\
\text { therapy }\end{array}$ & $\begin{array}{l}\text { Prolonged } \\
\text { EFS and OS }\end{array}$ & [17-19] \\
\hline & AMG330 & BiTE & Monotherapy & $\mathrm{r} / \mathrm{r}$ AML & Phase I & CR/CRi/MLFS & 02520427 \\
\hline & AMG673 & BiTE & Monotherapy & $\mathrm{r} / \mathrm{r}$ AML & Phase I & CRi & 03224819 \\
\hline & AMV564 & BiTE & Monotherapy & $\mathrm{r} / \mathrm{r}$ AML & Phase I & CR/CRi/PR & 03144245 \\
\hline & IMGN779 & $\mathrm{ADC}$ & Monotherapy & $\mathrm{r} / \mathrm{r}$ AML & Phase I & $\begin{array}{l}\text { Blast } \\
\text { reduction }\end{array}$ & 02674763 \\
\hline & JNJ-67371244 & BiTE & Monotherapy & $\mathrm{r} / \mathrm{r}$ AML & Phase I & $\mathrm{N} / \mathrm{A}$ & 03915379 \\
\hline & CAR T-cells & CAR T-cells & Monotherapy & $\mathrm{r} / \mathrm{r}$ AML & Phase I/II & $\mathrm{N} / \mathrm{A}$ & 03971799 \\
\hline CD25 & $\begin{array}{l}\text { Camidanlumab } \\
\text { tesirine }\end{array}$ & $\mathrm{ADC}$ & Monotherapy & $\mathrm{r} / \mathrm{r}$ AML & $\begin{array}{c}\text { Phase I, } \\
\text { development } \\
\text { stopped for AML }\end{array}$ & CRi & 02588092 \\
\hline CD47 & Magrolimab & $\mathrm{mAb}$ & Azacitidine & MDS/AML & $\begin{array}{c}\text { Phase I; } \\
\text { randomized, } \\
\text { double-blind } \\
\text { phase III trial for } \\
\text { untreated } \\
\text { high-risk MDS } \\
\text { patients } \\
\text { (ENHANCE, } \\
\text { NCT04313881) }\end{array}$ & $\begin{array}{l}\text { Improved } \\
\text { CR/CRi }\end{array}$ & $\begin{array}{l}03248479 \\
04313881\end{array}$ \\
\hline CD70 & Cusatuzumab & $\mathrm{mAb}$ & $\begin{array}{l}\text { Azacitidine/ } \\
\text { Venetoclax; } \\
\text { Azacitidine; } \\
\text { Monotherapy }\end{array}$ & $\begin{array}{l}\text { de novo } \\
\text { AML, } \\
\text { r/r AML }\end{array}$ & Phase I & $\begin{array}{l}\text { Improved } \\
\text { CR/CRi }\end{array}$ & 04150887 \\
\hline \multirow{7}{*}{ CD123 } & Flotetuzumab & DART & Monotherapy & $\mathrm{r} / \mathrm{r}$ AML & Phase I/II & $\mathrm{CR} / \mathrm{CRi}$ & 02152956 \\
\hline & IMGN632 & $\mathrm{ADC}$ & $\begin{array}{l}\text { Azacitidine/ } \\
\text { Venetoclax }\end{array}$ & r/r AML & Phase I/II & $\mathrm{CR} / \mathrm{CRi}$ & 04086264 \\
\hline & Vibecotamab & BiTE & Monotherapy & $\mathrm{r} / \mathrm{r}$ AML & Phase I & CR/CRi/MLFS & 02730312 \\
\hline & APVO436 & BiTE & Monotherapy & $\mathrm{r} / \mathrm{r} \mathrm{AML}$ & Phase I & PR & 03647800 \\
\hline & Tagraxofusp & $\mathrm{ADC}$ & $\begin{array}{l}\text { Azacitidine/ } \\
\text { Venetoclax }\end{array}$ & $\begin{array}{l}\text { r/r AML, } \\
\text { BPDCN }\end{array}$ & $\begin{array}{c}\text { Phase I; } \\
\text { tagraxofusp as } \\
\text { monotherapy: } \\
\text { approved for } \\
\text { BPDCN }\end{array}$ & $\mathrm{N} / \mathrm{A}$ & 03113643 \\
\hline & Talacotuzumab & $\mathrm{mAb}$ & Decitabine & $\begin{array}{l}\text { de novo } \\
\text { AML }\end{array}$ & $\begin{array}{l}\text { Phase II/III, } \\
\text { halted } \\
\text { prematurely in } \\
\text { its clinical } \\
\text { development }\end{array}$ & $\begin{array}{l}\text { No improve- } \\
\text { ment }\end{array}$ & 02472145 \\
\hline & UniCAR & CAR T-cells & Monotherapy & $\begin{array}{l}\text { r/r AML, } \\
\text { MDS, } \\
\text { BPDCN }\end{array}$ & Phase I & $\mathrm{N} / \mathrm{A}$ & 04230265 \\
\hline
\end{tabular}


Table 1. Cont.

\begin{tabular}{|c|c|c|c|c|c|c|c|}
\hline Target & Drug Name & Drug Type & Therapy & Indication & $\begin{array}{c}\text { Developmental } \\
\text { Stage }\end{array}$ & $\begin{array}{l}\text { Available } \\
\text { Results }\end{array}$ & $\begin{array}{c}\text { NCT } \\
\text { Number/ } \\
\text { Reference }\end{array}$ \\
\hline $\begin{array}{l}\text { CLEC12A/ } \\
\text { CLL-1 }\end{array}$ & MCLA-117 & BiTE & Monotherapy & $\mathrm{r} / \mathrm{r}$ AML & Phase I & $\begin{array}{l}\text { MLFS, blast } \\
\text { reduction }\end{array}$ & 03038230 \\
\hline \multirow{5}{*}{$\begin{array}{l}\text { PD-1/ } \\
\text { CTLA-4 }\end{array}$} & Nivolumab & $\mathrm{mAb}$ & $\begin{array}{l}\text { Azacitidine, } \\
\text { Ipilimumab }\end{array}$ & $\begin{array}{l}\text { de novo } \\
\text { AML, } \\
\text { r/r AML }\end{array}$ & Phase II & $\mathrm{CR} / \mathrm{CRi}$ & 02397720 \\
\hline & Ipilimumab & $\mathrm{mAb}$ & $\begin{array}{l}\text { Azacitidine, } \\
\text { Nivolumab }\end{array}$ & $\begin{array}{l}\text { de novo } \\
\text { AML, } \\
\text { r/r AML }\end{array}$ & Phase II & $\mathrm{CR} / \mathrm{CRi}$ & 02397720 \\
\hline & \multirow{3}{*}{ Pembrolizumab } & \multirow{3}{*}{$\mathrm{mAb}$} & Azacitidine & $\begin{array}{l}\text { MRD+ AML } \\
\text { in CR }\end{array}$ & Phase II & $\mathrm{N} / \mathrm{A}$ & 03769532 \\
\hline & & & $\begin{array}{l}\text { Azacitidine/ } \\
\text { Venetoclax; } \\
\text { Intensive } \\
\text { chemotherapy }\end{array}$ & $\begin{array}{l}\text { de novo } \\
\text { AML }\end{array}$ & $\begin{array}{l}\text { Phase II } \\
\text { Phase II }\end{array}$ & $\mathrm{N} / \mathrm{A}$ & $\begin{array}{l}04284787 \\
04214249\end{array}$ \\
\hline & & & Decitabine & $\begin{array}{l}\text { de novo } \\
\text { AML }\end{array}$ & Phase I & $\mathrm{CR}, \mathrm{SD}$ & 03969446 \\
\hline \multirow{2}{*}{ TIM-3 } & \multirow{2}{*}{ Sabatolimab } & \multirow{2}{*}{$\mathrm{mAb}$} & $\begin{array}{l}\text { Decitabine or } \\
\text { azacitidine }\end{array}$ & $\begin{array}{l}\text { de novo } \\
\text { AML }\end{array}$ & Phase I & $\mathrm{CR} / \mathrm{CRi}$ & 03066648 \\
\hline & & & $\begin{array}{l}\text { Azacitidine/ } \\
\text { Venetoclax }\end{array}$ & $\begin{array}{l}\text { de novo } \\
\text { AML }\end{array}$ & $\begin{array}{c}\text { Phase II } \\
\text { Phase I/II }\end{array}$ & $\mathrm{N} / \mathrm{A}$ & $\begin{array}{l}04150029 \\
04623216\end{array}$ \\
\hline $\begin{array}{l}\text { CD33/ } \\
\text { CLL-1 }\end{array}$ & CAR T-cells & CAR T-cells & $\mathrm{N} / \mathrm{A}$ & $\mathrm{r} / \mathrm{r}$ AML & Phase I & $\begin{array}{c}\text { MRD } \\
\text { negative, } C R\end{array}$ & 03795779 \\
\hline CD38 & CAR T-cells & CAR T-cells & $\mathrm{N} / \mathrm{A}$ & r/r AML & Phase I/II & $\mathrm{N} / \mathrm{A}$ & 04351022 \\
\hline PRAME & $\begin{array}{l}\text { TCR- } \\
\text { modified } \\
\text { T-cells }\end{array}$ & $\begin{array}{l}\text { TCR- } \\
\text { modified } \\
\text { T-cells }\end{array}$ & $\mathrm{N} / \mathrm{A}$ & $\begin{array}{l}\text { r/r AML, } \\
\text { MDS }\end{array}$ & Phase I/II & $\mathrm{N} / \mathrm{A}$ & 03503968 \\
\hline $\mathrm{N} / \mathrm{A}$ & $\begin{array}{c}\text { CAR } \\
\text { NK-cells }\end{array}$ & $\begin{array}{c}\text { CAR } \\
\text { NK-cells }\end{array}$ & $\mathrm{N} / \mathrm{A}$ & $\mathrm{r} / \mathrm{r}$ AML & Phase I & $\mathrm{N} / \mathrm{A}$ & 04623944 \\
\hline
\end{tabular}

Abbreviations: ADC, antibody drug conjugates; AML, acute myeloid leukemia; BiTE, bispecific T cell engagers, $\mathrm{BPDCN}$, blastic plasmadendritic cell neoplasm; CAR, chimeric antigen receptor; $\mathrm{CD}$, cluster of differentiation CLEC12A, C-type lectin domain family 12 member A; CLL-1, C-type lectin-like molecule-1; CTLA-4, cytotoxic Tlymphocyte-associated protein $4 ; \mathrm{CR}$, complete remission; $\mathrm{CRi}$, complete remission with incomplete hematological recovery; DART, dual-affinity retargeting antibody; EFS, event-free survival; EMA, European Medical Agency; FDA, Food and Drug Administration; mAB, monoclonal antibody; MRD, measurable residual disease; MDS, myelodysplastic syndrome; MLFS, morphologic leukemia free state; N/A, not applicable; OS, overall survival PD-1, programmed cell death protein 1; PR, partial remission; $r / r$, relapse/refractory; PRAME, preferentially expressed antigen of melanoma; SD, stable disease; TCR, T cell-receptor; TIM-3, T-cell immunoglobulin and mucin-domain containing-3.

\section{Clinical Evaluation of Different Approaches}

\subsection{Antibody Drug Conjugates}

One of the first major antigens in the focus of translational research is CD33, also known as Siglec-3 (sialic acid binding Ig-like lectin 3). This transmembrane receptor is overexpressed on leukemic blasts and stem cells and marks myeloid differentiation. Upon activation, it dimerizes and is internalized, rendering it an ideal candidate as a targeted treatment [20].

\subsubsection{Gemtuzumab Ozogamicin (GO; Anti-CD33 Monoclonal Antibody)}

Currently, gemtuzumab ozogamicin (GO), an anti-CD33 monoclonal antibody, is the only approved therapeutic agent targeting CD33 [20,21]. However, both medical agencies (FDA and EMA) have used different labels, as the FDA indicates the use of GO for both 
newly diagnosed as well as relapsed or refractory $(r / r)$ CD33-positive AML in adults, whereas the EMA indicates its use only for newly diagnosed AML [17,18,22,23]. After initial approval of GO in 2000, the pharmaceutical company withdrew GO from the market due to an increased mortality rate. GO was eventually re-approved in 2017 after a metaanalysis of 3325 adults demonstrated a survival benefit in patients with favorable- and intermediate-risk cytogenetics [19].

In comparison, early clinical trials of the unconjugated CD33 mAb lintuzumab without an added cytotoxic substance showed no clinical efficacy [24], yet clinical trials using conjugations with short-lived radionuclides such as 225Ac ( $\alpha$-particle decay) are underway (e.g., triple combination of venetoclax, azacitidine and lintuzumab-Ac225 in r/r AML patients (NCT03932318)).

\subsubsection{IMGN779 (ADC)}

An additional CD33 ADC is IMGN779, which uses a novel DNA-alkylating payload and demonstrated pre-clinical activity in cell lines and xenograft models [25]. A phase I study (NCT02674763) has been completed and demonstrated limited clinical efficacy. Seventy-nine percent of 50 patients, treated with different intravenous administration schedules and doses up to $0.7 \mathrm{mg} / \mathrm{kg}$, showed a decrease in peripheral circulating blasts and $41 \%$ demonstrated a $>30 \%$ reduction in bone marrow blast cells. The most frequently observed adverse event (AE) was febrile neutropenia in $40 \%$ of patients.

\subsubsection{Camidanlumab Tesirine (ADC, Development Stopped for AML)}

The ADC camidanlumab tesirine (also known as ADCT-301), which is directed against CD25 ( $\alpha$-subunit of the interleukin-2 receptor), was evaluated in a phase I trial for patients with $\mathrm{r} / \mathrm{r}$ AML or ALL (NCT02588092). Camidanlumab tesirine was given intravenously every three weeks, which was later changed to weekly administration. Of the 35 enrolled patients, 16 had post-baseline disease evaluation, of which two showed a CRi. The most common Grade $\geq 3$ treatment-emergent AEs were febrile neutropenia (25.7\%), as well as laboratory findings, such as lymphopenia, neutropenia, thrombocytopenia ( $14.3 \%$ each). Pneumonia, increased gamma-glutamyltransferase, and hypophosphatemia occurred in $11.4 \%$ each [26]. However, the study was terminated prematurely due to slow recruitment, limited efficacy in this population and early efficacy signals in lymphoma.

\subsubsection{Cusatuzumab (Anti-CD70 Antibody)}

Cusatuzumab (anti-CD70 antibody, formerly known as ARGX-110) combined with azacitidine indicates promising results in older patients with newly diagnosed AML of $83 \%(n=10 / 12)$ [27]. Currently, a phase I clinical trial examining the efficacy of the triple combination therapy of cusatuzumab, venetoclax and azacitidine is ongoing (NCT04150887). However, triple combinations of antibody therapy as well as venetoclax + azacitidine are likely to be associated with a high degree of hematological and non-hematological toxicities, such as prolonged cytopenia as well as febrile neutropenia as compared to venetoclax + azacitidine.

\subsubsection{IMGN632 (ADC)}

The CD123 antibody IMGN632 is conjugated to an alkyl-benzodiazepine and was investigated as a single-agent in 74 patients ( 7 patients with blastic plasmadendritic cell neoplasm (BPDCN) and 67 patients with AML). The dosage ranged from 0.045 to $0.3 \mathrm{mg} / \mathrm{kg}$ IMGN632 per course. Fifty-five percent of the patients with AML showed a reduction in bone marrow blast cells and $20 \%$ achieved a CR/CRi. Additionally, $43 \%$ of patients with BPDCN achieved a CR/CRi. The most common AEs included diarrhea (30\%; all $\leq$ grade 2$)$, febrile neutropenia ( $27 \%$; all grade 3$)$, nausea ( $26 \%$; one grade 3$)$, chills ( $23 \%$; all $\leq$ grade 2$)$, and lung infection $(22 \% ; \geq$ grade 2$)$. The principal treatment-related AEs were infusionrelated reactions ( $16 \%$; four grade 3$)$, which included chills, nausea, diarrhea and tachycardia. However, none required treatment discontinuation [28]. 
Several studies are currently ongoing evaluating IMGN632 as monotherapy in patients with $\mathrm{r} / \mathrm{r}$ BPDCN and MRD-positive AML or in combination with azacitidine and/or venetoclax (NCT04086264) [29].

\subsubsection{Tagraxofusp (ADC)}

Tagraxofusp is an intravenously administered CD123-directed cytotoxin. This treatment was approved by the FDA as treatment of patients aged $\geq 2$ years with BPDCN in December 2018 [30], based on a publication showing 90\% ORR in treatment-naive patients of whom $45 \%$ reached CR. The 2-year overall survival (OS) rate was 52\% [31]. Forty-five percent $(n=13 / 29)$ of the patients could be successfully bridged to allo-HSCT. Additionally, patients with relapsed/refractory BPDCN had an ORR of $67 \%$ and median OS of 8.5 months after treatment with tagraxofusp. Two deaths due to capillary leak syndrome occurred [31]. Currently, the triple combination of tagraxofusp, hypomethylating agents and venetoclax is being evaluated in an ongoing phase $1 / 2$ clinical trial in patients with newly diagnosed CD123-positive AML or high-risk MDS (NCT03113643).

\subsubsection{Talacotuzumab (ADC)}

The CD123 mAb talacotuzumab in a combined therapy with decitabine was halted prematurely in its clinical development after showing an unfavorable benefit/risk ratio and insufficient efficacy in a phase II/III trial (NCT 02472145). No difference in the CR rate could be observed between patients receiving decitabine monotherapy (11\% vs. 15\%; $p=0.44$ ) or the combination therapy of decitabine with $9 \mathrm{mg} / \mathrm{kg}$ talacotuzumab. The most common AEs leading to death included sepsis (4.8\%), multiple organ dysfunction $(5.4 \%)$, pneumonia $(3.4 \%)$, septic shock (3.4\%) and sudden death $(0.7 \%)$. The most common reported infusion-related AEs were chills (16.3\%), pyrexia (5.4\%), and hypoxia (4.8\%) [32].

\subsection{Bispecific Antibodies (CD3 $x$ AML Antigen)}

\subsubsection{AMG330 (BiTE)}

AMG330, a BiTE anti-CD33 and anti-CD3-antibody, demonstrated potent antibodymediated cytotoxicity in experimental AML cell lines and xenotransplantation models [33-35]. AMG330 is currently being evaluated in an ongoing phase I trial for $r / r$ AML patients (NCT02520427). Due to its short half-life of less than two hours, AMG330 has to be administered as a continuous intravenous infusion with doses up to $720 \mu \mathrm{g} /$ day. Updated results have been published [36]. So far, 8 of 42 evaluable patients showed responses consisting of three CRs, four CRis and one morphologic leukemia-free state (MLFS). As expected, the most frequent observed AE was cytokine release syndrome (CRS), which occurred in two-thirds of the patients and with grade 3 or higher in $13 \%$ of patients. It correlated with both dose level and disease burden.

\subsubsection{AMG673 (BiTE)}

As stated before, the short half-life of AMG330 renders continuous infusion necessary. AMG673 is a modified CD33/CD3 BiTE with an extended half-life due to fusion of an additional IgG Fc chain, allowing a drastic reduction in infusion times in an ongoing phase I trial (NCT03224819), which is active, but currently not recruiting. Out of 38 patients, treated with doses up to $110 \mu \mathrm{g}, 27$ were evaluable. A blast cell reduction $\geq 50 \%$ could be observed in six patients. One patient achieved a CRi and went on to allo-HSCT. Overall, $63 \%$ of the patients showed a CRS, which was grade 3 or higher in $18 \%$ of these patients. In addition, treatment-emergent SAEs were reported in $68 \%$, with infections (34\%) being the most common [37].

\subsubsection{AMV564 (BiTE)}

Another bispecific CD33/CD3 antibody is AMV564, currently under investigation in a phase I trial for patients with r/r AML (NCT03144245). So far, 36 patients could be enrolled 
with doses up to $300 \mu \mathrm{g} /$ day and no grade 3 or higher CRS was observed. Thirty-five patients were evaluable and one CR, one CRi and one PR have been achieved [38].

\subsubsection{JNJ-67371244 (BiTE)}

The bispecific antibody JNJ-67371244 is being investigated in an ongoing phase I trial (NCT03915379) for patients with $\mathrm{r} / \mathrm{r}$ AML or MDS. Patients are receiving the antibody either subcutaneously or intravenously and must not be eligible for allo-HSCT. No preliminary data have been published yet.

\subsubsection{Flotetuzumab (DART Antibody)}

The alpha chain of the interleukin-3 receptor, also known as CD123, is expressed on hematopoietic stem/progenitor cells (HSPCs) and myeloid cells and strongly on leukemic stem cells. Increased CD123 expression is associated with higher risk of relapse [39].

Currently, flotetuzumab, a combined CD123- and CD3-DART antibody, was evaluated in a phase I/II trial in 88 patients $\geq 18$ years with $\mathrm{r} / \mathrm{r}$ AML (NCT02152956) [40], and in patients up to 20 years with relapsed or refractory MDS (NCT04158739). The recommended phase II dose was $500 \mathrm{ng} / \mathrm{kg} /$ day by continuous infusion. The dosage was escalated during the first week of treatment. Pre-medication included 10-20 mg i.v. dexamethasone. A CR/CRi rate of 30\% was reached and a median OS of 10.2 months (range, 1.9-27.3 months) could be observed, with 6- and 12-month survival rates of $75 \%$ and $50 \%$. CRS occurred in almost all patients (grade 3 in $8 \%$ ). Most cases were transient and reversible and $32 \%$ of CRS events were observed in the first week of therapy during step-up dosing. Strategies to mitigate CRS included the early use of tocilizumab as well as lead-in dosing [40].

\subsubsection{XmAb 14045 (BiTE)}

In an ongoing phase I dose-escalation study (NCT02730312) for r/r AML patients, the CD123/CD3 bispecific antibody vibecotamab (also known as XmAb 14045 or SQZ622) is being evaluated. In a preliminary report, 104 AML patients, 1 CML patient and 1 patient with B-ALL with a median of three prior lines of therapy were treated with weekly iv administrations and a dosage ranging from $0.003 \mu \mathrm{g} / \mathrm{kg}$ to $12 \mu \mathrm{g} / \mathrm{kg}$. In higher dose levels $(0.75 \mu \mathrm{g} / \mathrm{kg})$, response could be achieved with an ORR of $14 \%(n=7 / 51, \mathrm{CR} / \mathrm{CRi} / \mathrm{MLFS})$ and a fast onset of antileukemic activity. As expected, CRS was the most frequent $\mathrm{AE}$, occurring in 62 of 106 patients ( $85 \%$ grade $1-2,15 \%$ grade $\geq 3$ ). Additional mild to moderate AEs were associated with CRS, such as chills, fever, tachycardia, and hypotension and occurred in $24 \%$ of the patients. No myelosuppression requiring dose modification or tumor lysis syndrome occurred [41].

\subsubsection{APVO436 (BiTE)}

Another bispecific CD123/CD3 antibody is APVO436, which is currently being evaluated in an ongoing phase I trial (NCT03647800). The study recruits r/r AML and MDS patients, not fit for intensive chemotherapy or allo-HSCT. Preliminary results of 34 evaluable patients with $\mathrm{r} / \mathrm{r}$ AML receiving a weekly infusion of APVO436 at dose levels between $0.3 \mu \mathrm{g} / \mathrm{kg}$ and $60 \mu \mathrm{g} / \mathrm{kg}$ demonstrate antileukemic activity, with two patients achieving a PR, which later deepened to CR; additionally, six patients showed prolonged stable disease (SD). Manageable side effects included CRS in $21.7 \%$ of the patients (grade $\geq 3$ in $8.7 \%$ of patients) [42].

\subsubsection{CLEC12A/CLL-1: MCLA-117 (BiTE)}

The bispecific mAb MCLA-117 uses another target in combination with CD3, namely CLEC12A (also known as CLL-1, C-type Lectin-like molecule 1) and is currently under investigation in an ongoing phase I trial (NCT03038230). CLEC12A is highly expressed on AML blasts and LSCs, potentially resulting in superior eradication while saving normal hematopoietic stem cells. Patients with $\mathrm{r} / \mathrm{r}$ AML or very high risk MDS can be included. After an initial ramp-up phase, a weekly infusion of the target dose is being administered. 
Out of 58 evaluable patients, six patients demonstrated a blast cell reduction $\geq 50 \%$ from baseline, including one patient with MLFS, whereas $36.2 \%$ of patients experienced CRS (8.6\% with grade 3 or higher). No dose-limiting toxicities (DLTs) have been observed [43].

\subsection{Immune Checkpoint Inhibitors}

\subsubsection{PD-L1, PD-1 and CTLA-4 Inhibitors}

Immune checkpoint inhibitors have shown only very modest clinical efficacy as single agents in patients with $\mathrm{r} / \mathrm{r}$ AML [44]. However, treatment with hypomethylating agents (HMAs) has shown to upregulate the surface expression of PD-L1, PD-1, PD-L2 and CTLA-4 $[45,46]$. Patients with the highest expression tend to have poor survival and the shortest period of response to HMA therapy. Thus, the combination of HMAs and immune checkpoint inhibitors may improve outcome [47].

\section{- $\quad$ Avelumab (PD-L1 Antibody)}

The PD-L1 antibody avelumab in combination with azacitidine was recently evaluated in a phase $\mathrm{Ib} / \mathrm{II}$ study in 19 patients with $\mathrm{r} / \mathrm{r}$ AML [48]. The most common grade $\geq 3$ treatment-related AEs were neutropenia and anemia in 2 patients each. The clinical benefit was only marginal with an overall CRi rate of $10.5 \%$, and a median OS of 4.8 months. However, PD-L2 expression measured by mass cytometry was significantly higher as compared with PD-L1 on AML blasts from all patients who were analyzed at all time points. These data suggest a novel potential role for PD-L2 as a means of AML immune escape. Another PD-L1 antibody, atezolizumab, was evaluated in combination with immunomodulatory agents in a phase 1 study (NCT02892318).

\section{- Nivolumab (Anti-PD1 Antibody)}

Nivolumab as combined therapy with azacitidine was recently evaluated in an open label, single arm phase I/II study in 70 patients with r/r AML [49]. The ORR was 33\% (whole cohort, HMA pretreatment allowed) including $15(22 \%)$ patients with CR/CRi, and $58 \%$ in HMA-treatment naïve patients. Pre-therapeutic analysis of CD3 and CD8 in bone marrow and peripheral blood by flow cytometry were significantly predictive for outcome and response. Grade 2-4 immune-toxicity-associated AEs, such as skin rash, pneumonitis, infections, nephritis, hypophysitis, increased transaminases as well as colitis occurred in $20-25 \%$ of the patients and were in 95\% reversible, if steroids were started within $24 \mathrm{~h}$ [49].

A phase I/II trial (NCT02397720) evaluating azacitidine, nivolumab and ipilimumab is currently recruiting in patients with $\mathrm{r} / \mathrm{r}$ AML. A CR/CRi rate of 19\% $(n=7 / 36)$ and PR in $3 \%(n=1)$ could be observed. Interestingly, three of four patients with extramedullary disease achieved PR/CR with a median duration of 8 months. The mortality rate was very low with 0 and $6 \%$ after four and eight weeks, respectively. Eight patients $(19 \%)$ had grade 3 or higher immune toxicities including rash, pneumonitis, colitis, and pyrexia. No deaths caused by immune toxicity occurred. The response correlates with the extension of a cluster of antigen-experienced CD8+ T cells. One-year OS in $\mathrm{r} / \mathrm{r}$ AML patients after treatment with azacitindine/nivolumab/ipilimumab was $25 \%$. The median OS of 6-8 months after the combined therapy is comparable to that reported with hypomethylating agents and venetoclax salvage in numerous studies [50].

Future directions include the evaluation of the combined therapy of azacitidine + venetoclax and nivolumab in elderly patients ( $\geq 65$ years) with either newly diagnosed or $\mathrm{r} / \mathrm{r}$ AML.

\section{- Pembrolizumab (Anti-PD1 Antibody)}

For the anti-PD-1 mAb pembrolizumab, several trials aiming to implement the additional therapeutic option at different disease stages are underway. Two randomized phase II studies are evaluating pembrolizumab as first-line treatment for patients not eligible for intensive chemotherapy in combination with azacitidine and venetoclax or with intensive chemotherapy for eligible patients, respectively (NCT04284787, NCT04214249). However, no published data are available yet. Another phase I trial (NCT03969446) investigates the addition of pembrolizumab to decitabine in newly diagnosed AML or high-risk MDS as 
well as in r/r AML patients. Preliminary results in a small cohort have been reported [51]. Ten high-risk AML patients were treated with pembrolizumab $200 \mathrm{mg}$ every 3 weeks and decitabine $20 \mathrm{mg} / \mathrm{m}^{2}$ for a total of 10 days for up to eight cycles. This treatment led to an MRD-negative CR in one, SD and progressive disease in four patients each; one patient did not complete the study. The treatment was well tolerated; no grade $5 \mathrm{AE}$ occurred. Most grade 4 AEs were hematological. Grade 4 sepsis occurred in two patients. Two patients suffered from hypothyroidism and a third patient developed central diabetes insipidus, possibly associated with pembrolizumab [51].

In addition, pembrolizumab is under investigation as additional agent when using MRD-triggered treatment in combination with azacitidine (PEMAZA, NCT03769532) in patients harboring a NPM1-mutation, who are in hematological CR but MRD-positive.

- $\quad$ Ipilimumab (CTLA-4 inhibitor)

Treatment with the anti-CTLA-4 monoclonal antibody ipilimumab showed clinical activity in relapsed patients with hematological malignancies after allo-HSCT, including 5 of 14 patients with AML, who achieved CR [52]. Grade 3/4 immune-related AEs occurred in $25 \%$ of the patients within the trial. A phase 1 trial on the combination of ipilimumab and CD25/Treg-depleted DLI in patients with relapsed myeloid diseases after matched-HCT is currently ongoing (NCT03912064).

\subsubsection{T-Cell Immunoglobin and Mucin Domain 3 (TIM-3) Inhibitor}

Another potent immune checkpoint is T-cell immunoglobin and mucin domain 3 (TIM-3), which is expressed by LSCs as well as a multitude of immune cells.

\section{- Sabatolimab}

Sabatolimab (MBG453) is an antibody-based inhibitor, which is being evaluated in an ongoing phase I trial (NCT03066648) in combination with either azacitidine or decitabine [53]. Fourteen of 34 (41\%) evaluable patients with newly diagnosed AML showed a response (three patients with PR, three with CRi, and eight patients with CR, respectively). The most common grade 3 or higher treatment-emergent AEs were thrombocytopenia (45.8\%), neutropenia (50\%), febrile neutropenia $(29.2 \%)$, anemia $(27.1 \%)$, and pneumonia $(10.4 \%)$. However, only three patients needed to discontinue the therapy. One dose-limiting toxicity occurred (grade 3 ALT elevation); the maximum tolerated dose was not reached with either combination [53].

Currently, trials investigating the combination therapy with venetoclax are enrolling patients (NCT04150029, NCT04623216).

\subsubsection{Macrophage-Based Inhibitor}

\section{- Magrolimab}

The antibody magrolimab, which targets CD47 as a macrophage immune checkpoint inhibitor, is evaluated in several early clinical trial studies in AML. A phase I trial of magrolimab with azacitidine led to an overall response rate (ORR) of $91 \%$ in patients with MDS and a CR rate of $42 \%$. In addition, high response rates were observed in TP53-mutated MDS patients (NCT03248479). Of note, AML patients with a TP53 mutation $(n=12)$ showed a CR/CRi rate of $75 \%$. With a median follow-up of 8.8 months, the median duration of response or OS was not met. The therapy was well tolerated, and no treatment-related febrile neutropenia occurred. Common treatment-related AEs were anemia (44\%), fatigue $(18 \%)$, infusion reaction (18\%), neutropenia (8\%) and thrombocytopenia (5\%). In addition, no patient discontinued due to an AE. The mean decline in hemoglobin levels with the first dose of magrolimab + azacitidine was only $0.4 \mathrm{~g} / \mathrm{dL}$. Fifty-eight percent of the patients became red blood cell transfusion independent [54].

Altogether, these promising results demonstrate the clinical applicability of macrophage checkpoint blockade. Currently, these observations are being further elucidated in a randomized, double-blind phase III trial for untreated high-risk MDS patients (ENHANCE, NCT04313881) [55]. 


\subsection{CAR-T Cell Approaches}

The principle of chimeric antigen receptor T-cells (CAR T-cells) has had great success in the field of lymphatic diseases, with EMA and FDA approved CAR T-cells for the treatment of multiple myeloma, mantle cell lymphoma and relapsed or refractory diffuse large B-cell lymphoma, respectively. It applies the method of transduction of patient-derived T-cells using viral vectors, thus leading to the expression of genetically modified T-cell receptors and independent tumor-specific antigen recognition, regardless of the presence of co-stimulatory molecules. However, translating this achievement to the field of myeloid malignancies has proven to be difficult as potential target antigens are rare and the specific immune microenvironment of AML is hostile towards immunogenic attack [56]. Moreover, most potential targets are also being expressed by normal hematopoietic stem cells, increasing potential off-target effects and harming the recovery of normal bone marrow. Various approaches are currently under investigation to circumvent these obstacles, as discussed below.

\section{- CD33-CLL-1-CAR-T}

Using a unique dual specific approach, an ongoing phase I, first-in-human trial utilized CD33-CLL-1 CAR T-cells in nine patients with r/r AML (NCT03795779) [57]. Four weeks after CAR T-cell infusion, seven patients reached MRD-negativity using flow cytometry, of which six moved on to subsequent allo-HSCT, thus indicating that this might be a strategy to overcome some of the limitations of CAR T-cell therapy. As expected, CRS occurred in almost all patients ( $n=8 ; 3$ grade I, 3 grade II, and 2 grade III) and neurotoxicity in 4 patients (1 grade I and 3 grade III). Pancytopenia grade IV occurred in all patients. Sepsis and pneumonia occurred in three patients each and fungal infection in two patients. All AEs were resolved after treatment. Early intervention with steroids reduced CRS and neurotoxicity [57].

\section{- CD33-CAR-T}

The approach of CAR-T cells targeting CD33 is also under examination as a potential immune-based therapy. Currently, a phase I/II trial using a CD33-CAR-T cell is being evaluated in children and young adults with r/r AML (NCT03971799). The construct, using linutuzumab-CD28/CD3 , has shown robust in vitro and in vivo activity against cell lines and patient-derived xenograft models [58].

\section{- CAR-T-38}

The antigen CD38, expressed on mainly leukocyte subtypes and well known as suitable target for the therapy of multiple myeloma, is also a target for CAR T-cells in r/r AML. Currently, this approach is being evaluated in a phase I/II trial (NCT04351022). Currently, results on six relapsed AML patients after allo-HSCT are available [59]. All patients exhibited CD38 in more than $90 \%$ on their blast cells. Four weeks after the CAR-T-38 cells infusion, four of six $(66.7 \%)$ patients achieved CR or CRi. However, the median duration of CR or CRi was only 6.4 months (range 3.9-8.7 months) and the cumulative relapse rate at 6 months was $50 \%$. Median OS and leukemia-free survival were 7.9 and 6.4 months, respectively. Thus, further approaches are needed to maintain CR/CRi after CAR-T cell approaches. Regarding toxicity, grade I-II CRS occurred in five patients and grade III hepatotoxicity in one patient. All AEs were transient and clinically manageable. Pancytopenia was present in all patients before CAR-T-38 infusion, and neutropenia persisted during CAR-T-38 therapy. The median duration of neutropenia was 22 (range, 7-35) days. The median duration of platelet recovery was 25 (range, 18-123) days. No neurological toxicities or severe infections occurred [59]. 


\section{- UniCAR}

A modification on the CAR-T cell approach is the universal CAR-T platform (UniCAR), in which a universal adapter molecule with a short half-life is being continuously infused intravenously. This allows for quick cessation of CAR-T side effects such as CRS or immune effector cell-associated neurotoxicity syndrome (ICANS) and is currently being explored in a phase I trial (NCT04230265) [60,61]. Very recently, the results of three patients that were dosed and had completed treatment within the UniCAR trial were reported [62]. All patients showed a response (one PR and two CRi). AML was still under control 100 days after UniCAR administration in one patient, whereas another patient relapsed after one month. So far, no DLTs were observed. In two patients, grade 1 CRS occurred, which were manageable within two days with antipyretics [62].

Another approach is to use T-cell receptor (TCR)-modified T-cells, which do not express a CAR, while also targeting a specific antigen. One such antigen is the preferentially expressed antigen of melanoma (PRAME), which has been shown to be a potential target for AML therapy in concurrence with specific human leukocyte antigen (HLA) restrictions. A phase I/II trial (NCT03503968) using such T-cells is currently underway.

- CAR natural killer cells

Finally, an alternative approach is to exploit and take advantage of the potential of natural killer cells (NK-cells). An active, recruiting phase I trial (NCT04623944) uses allogeneic, genetically engineered CAR NK-cells (NKX101), which have been modified to express several co-stimulatory and signaling receptors as well as membrane bound interleukin-15 used as an autocrine growth factor [63]. Preclinical studies have shown anti-leukemic activity in xenograft models.

\subsection{Vaccination Approaches}

Another strategy to combat AML presented here is the use of vaccination-based ideas in order to harness the immune systems' ability to recognize leukemia-specific antigens through common pathways mediated by dendritic cells and T lymphocytes, among others. The most challenging issue for tumor vaccinations remains antigen selection. A recently published trial (NCT03697707) investigated the use of two different vaccination regimes using allogeneic dendritic cells in 12 advanced-stage elderly AML patients who were in CR, but MRD-positive. The study was based on a $3+3$ dose escalation design. Patients received four biweekly intradermal DCP-001 injections at different dose levels (10, 25, and 50 million cells DCP-001). The treatment was well tolerated. SAEs occurred in six patients, with a possible relationship to study treatment in one (diabetes insipidus). A median OS of 36 months (range, 7 to 63 months) was observed in patients with no circulating blasts in comparison to patients with circulating blasts, who died within 6 months. Maintained T cell levels and multi-functional immune responses were associated with long-term survival [64].

\section{Conclusions and Future Challenges}

Immune-based therapeutic approaches are an important asset in the fight against AML. Currently, there are many substances in development. However, most of the clinical data are mainly available in meeting presentations, since these trials are still in progress. Nevertheless, these preliminary data suggest an acceptable safety profile with promising efficacy. As expected, CRS is one of the most frequently observed AE, whereas neurotoxicity does not seem to be common. Currently, the only approved immune-based therapies are GO for AML and tagraxofusp for BPDCN. Further agents, used as monotherapy or in combination with chemotherapy or venetoclax + HMA, might provide long-term disease control including MRD negativity. However, more studies are needed to evaluate the impact on patient outcomes. 


\begin{abstract}
Author Contributions: The authors confirm contribution to the manuscript as follows: article conception and design: M.B. and S.K.; data collection: M.B. and S.K.; analysis and interpretation of results: M.B. and S.K.; draft manuscript preparation: M.B. and S.K. All authors have read and agreed to the published version of the manuscript.
\end{abstract}

Funding: This research received no external funding.

Conflicts of Interest: S.K. has served as a consultant for Novartis, Pfizer and Jazz Pharmaceuticals. M.B. declares no conflict of interest.

\title{
References
}

1. Papaemmanuil, E.; Gerstung, M.; Bullinger, L.; Gaidzik, V.I.; Paschka, P.; Roberts, N.D.; Potter, N.E.; Heuser, M.; Thol, F.; Bolli, N.; et al. Genomic Classification and Prognosis in Acute Myeloid Leukemia. N. Engl. J. Med. 2016, 374, $2209-2221$. [CrossRef]

2. Swerdlow, S.H.; Campo, E.; Harris, N.L.; Jaffe, E.S.; Pileri, S.A.; Stein, H.; Thiele, J. WHO Classification of Tumours of Haema-Topoietic and Lymphoid Tissues, 4th ed.; WHO Press: Geneva, Switzerland, 2017.

3. Schlenk, R.F.; Frech, P.; Weber, D.; Brossart, P.; Horst, H.-A.; Kraemer, D.; Held, G.; Ringhoffer, M.; Burchardt, A.; Kobbe, G.; et al. Impact of pretreatment characteristics and salvage strategy on outcome in patients with relapsed acute myeloid leukemia. Leukemia 2017, 31, 1217-1220. [CrossRef] [PubMed]

4. Dombret, H.; Gardin, C. An update of current treatments for adult acute myeloid leukemia. Blood 2016, 127, 53-61. [CrossRef] [PubMed]

5. O'Donnell, M.R.; Tallman, M.S.; Abboud, C.N.; Altman, J.K.; Appelbaum, F.R.; Arber, D.A.; Bhatt, V.; Bixby, D.; Blum, W.; Coutre, S.E.; et al. Acute Myeloid Leukemia, Version 3.2017, NCCN Clinical Practice Guidelines in Oncology. J. Natl. Compr. Cancer Netw. 2017, 15, 926-957. [CrossRef] [PubMed]

6. Döhner, H.; Estey, E.; Grimwade, D.; Amadori, S.; Appelbaum, F.R.; Büchner, T.; Dombret, H.; Ebert, B.L.; Fenaux, P.; Lar-son, R.A.; et al. Diagnosis and management of AML in adults: 2017 ELN recommendations from an international expert panel. Blood 2017, 129, 424-447. [CrossRef]

7. Roboz, G.J. Current treatment of acute myeloid leukemia. Curr. Opin. Oncol. 2012, 24, 711-719. [CrossRef]

8. Kayser, S.; Levis, M.J. Updates on targeted therapies for acute myeloid leukaemia. Br. J. Haematol. 2021. [CrossRef]

9. Daver, N.; Alotaibi, A.S.; Bücklein, V.; Subklewe, M. T-cell-based immunotherapy of acute myeloid leukemia: Current con-cepts and future developments. Leukemia 2021, 35, 1843-1863. [CrossRef]

10. Chao, M.P.; Alizadeh, A.A.; Tang, C.; Jan, M.; Weissman-Tsukamoto, R.; Zhao, F.; Park, C.Y.; Weissman, I.L.; Majeti, R. Therapeutic Antibody Targeting of CD47 Eliminates Human Acute Lymphoblastic Leukemia. Cancer Res. 2010, 71, 1374-1384. [CrossRef]

11. Chao, M.P.; Alizadeh, A.A.; Tang, C.; Myklebust, J.H.; Varghese, B.; Gill, S.; Jan, M.; Cha, A.C.; Chan, C.K.; Tan, B.T.; et al. Anti-CD47 Antibody Synergizes with Rituximab to Promote Phagocytosis and Eradicate Non-Hodgkin Lymphoma. Cell 2010, 142, 699-713. [CrossRef]

12. Majeti, R.; Chao, M.P.; Alizadeh, A.A.; Pang, W.W.; Jaiswal, S.; Gibbs, K.D.; Van Rooijen, N.; Weissman, I.L. CD47 Is an Adverse Prognostic Factor and Therapeutic Antibody Target on Human Acute Myeloid Leukemia Stem Cells. Cell 2009, 138, $286-299$. [CrossRef] [PubMed]

13. Pang, W.W.; Pluvinage, J.V.; Price, E.A.; Sridhar, K.; Arber, D.A.; Greenberg, P.L.; Schrier, S.L.; Park, C.Y.; Weissman, I.L. Hematopoietic stem cell and progenitor cell mechanisms in myelodysplastic syndromes. Proc. Natl. Acad. Sci. USA 2013, 110, 3011-3016. [CrossRef] [PubMed]

14. Tseng, D.; Volkmer, J.-P.; Willingham, S.B.; Contreras-Trujillo, H.; Fathman, J.W.; Fernhoff, N.B.; Seita, J.; Inlay, M.A.; Weiskopf, K.; Miyanishi, M.; et al. Anti-CD47 antibody-mediated phagocytosis of cancer by macrophages primes an effective antitumor T-cell response. Proc. Natl. Acad. Sci. USA 2013, 110, 11103-11108. [CrossRef] [PubMed]

15. Allen, C.; Zeidan, A.M.; Bewersdorf, J.P. BiTEs, DARTS, BiKEs and TriKEs-Are Antibody Based Therapies Changing the Future Treatment of AML? Life 2021, 11, 465. [CrossRef]

16. Oluwole, O.O. Clinical experience of CAR T cell therapy in lymphomas. Best Pract. Res. Clin. Haematol. 2021, $34,101281$. [CrossRef]

17. Summary of Product Characteristics for Gemtuzumab Ozogamicin. Available online: https://www.ema.europa.eu/en/ documents/product-information/mylotarg-epar-product-information_en.pdf (accessed on 26 May 2021).

18. Highlights of Prescribing Information for Gemtuzumab Ozogamicin. Available online: https://www.accessdata.fda.gov/ drugsatfda_docs/label/2017/761060lbl.pdf (accessed on 27 May 2021).

19. Hills, R.K.; Castaigne, S.; Appelbaum, F.R.; Delaunay, J.; Petersdorf, S.; Othus, M.; Chilton, L.; Burnett, A.K.; Dombret, H.; Moorman, A.V.; et al. Addition of gemtuzumab ozo-gamicin to induction chemotherapy in adult patients with acute myeloid leukaemia: A meta-analysis of individual patient data from randomised controlled trials. Lancet Oncol. 2014, 15, 986-996. [CrossRef]

20. Thol, F.; Schlenk, R.F. Gemtuzumab ozogamicin in acute myeloid leukemia revisited. Expert Opin. Biol. Ther. 2014, 14, 1185-1195. [CrossRef] 
21. Godwin, C.D.; Gale, R.P.; Walter, R.B. Gemtuzumab ozogamicin in acute myeloid leukemia. Leukemia 2017, 31, 1855-1868. [CrossRef]

22. Bross, P.F.; Beitz, J.; Chen, G.; Chen, X.H.; Duffy, E.; Kieffer, L.; Roy, S.; Sridhara, R.; Rahman, A.; Williams, G.; et al. Ap-proval summary: Gemtuzumab ozogamicin in relapsed acute myeloid leukemia. Clin. Cancer Res. 2001, 7, 1490-1496.

23. Larson, R.; for the Mylotarg Study Group; Boogaerts, M.; Estey, E.; Karanes, C.; Stadtmauer, A.E.; Sievers, E.; Mineur, P.; Bennett, J.M.; Berger, M.S.; et al. Antibody-targeted chemotherapy of older patients with acute myeloid leukemia in first re-lapse using Mylotarg (Gemtuzumab ozogamicin). Leukemia 2002, 16, 1627-1636. [CrossRef]

24. Feldman, E.J.; Brandwein, J.; Stone, R.; Kalaycio, M.; Moore, J.; O’Connor, J.; Wedel, N.; Roboz, G.J.; Miller, C.; Chopra, R.; et al. Phase III Randomized Multicenter Study of a Humanized Anti-CD33 Monoclonal Antibody, Lintuzumab, in Combination with Chemotherapy, Versus Chemotherapy Alone in Patients With Refractory or First-Relapsed Acute Myeloid Leukemia. J. Clin. Oncol. 2005, 23, 4110-4116. [CrossRef]

25. Kovtun, Y.; Noordhuis, P.; Whiteman, K.R.; Watkins, K.; Jones, G.E.; Harvey, L.; Pinkas, J.; Adams, S.; Sloss, C.M.; Lai, K.C.; et al. IMGN779, a Novel CD33-Targeting Antibody-Drug Conjugate with DNA-Alkylating Activity, Exhibits Potent Anti-tumor Activity in Models of AML. Mol. Cancer Ther. 2018, 17, 1271-1279. [CrossRef] [PubMed]

26. Goldberg, A.D.; Atallah, E.; Rizzieri, D.; Walter, R.B.; Chung, K.Y.; Spira, A.; Stock, W.; Cruz, H.G.; Boni, J.; Chao, G.; et al. Camidanlumab tesirine, an anti-body-drug conjugate, in relapsed/refractory CD25-positive acute myeloid leukemia or acute lymphoblastic leu-kemia: A phase I study. Leuk. Res. 2020, 95, 106385. [CrossRef] [PubMed]

27. Riether, C.; Pabst, T.; Höpner, S.; Bacher, U.; Hinterbrandner, M.; Banz, Y.; Müller, R.; Manz, M.G.; Gharib, W.H.; Francisco, D.; et al. Targeting CD70 with cusatuzumab eliminates acute myeloid leukemia stem cells in patients treated with hypometh-ylating agents. Nat. Med. 2020, 26, 1459-1467. [CrossRef] [PubMed]

28. Daver, N.G.; Montesinos, P.; DeAngelo, D.J.; Wang, E.S.; Papadantonakis, N.; Deconinck, E.; Erba, H.P.; Pemmaraju, N.; Lane, A.A.; Rizzieri, D.A.; et al. Clinical Profile of IMGN632, a Novel CD123-Targeting Antibody-Drug Conjugate (ADC), in Patients with Relapsed/Refractory (R/R) Acute Myeloid Leukemia (AML) or Blastic Plasmacytoid Dendritic Cell Neoplasm (BPDCN). Blood 2019, 134, 734. [CrossRef]

29. Kantarjian, H.; Kadia, T.; DiNardo, C.; Daver, N.; Borthakur, G.; Jabbour, E.; Garcia-Manero, G.; Konopleva, M.; Ravandi, F. Acute myeloid leukemia: Current progress and future directions. Blood Cancer J. 2021, 11, 41. [CrossRef] [PubMed]

30. ELZONRIS; Stemline Therapeutics, Inc.: New York, NY, USA, 2018.

31. Pemmaraju, N.; Lane, A.A.; Sweet, K.L.; Stein, A.S.; Vasu, S.; Blum, W.; Rizzieri, D.A.; Wang, E.S.; Duvic, M.; Sloan, J.M.; et al. Tagraxofusp in Blastic Plasmacytoid Dendritic-Cell Neoplasm. N. Engl. J. Med. 2019, 380, 1628-1637. [CrossRef]

32. Montesinos, P.; Roboz, G.J.; Bulabois, C.E.; Subklewe, M.; Platzbecker, U.; Ofran, Y.; Papayannidis, C.; Wierzbowska, A.; Shin, H.J.; Doronin, V.; et al. Safety and efficacy of talacot-uzumab plus decitabine or decitabine alone in patients with acute myeloid leukemia not eligible for chemotherapy: Results from a multicenter, randomized, phase 2/3 study. Leukemia 2021, 35, 62-74. [CrossRef]

33. Krupka, C.; Kufer, P.; Kischel, R.; Zugmaier, G.; Bögeholz, J.; Köhnke, T.; Lichtenegger, F.S.; Schneider, S.; Metzeler, K.; Fiegl, M.; et al. CD33 target validation and sustained depletion of AML blasts in long-term cultures by the bispecific T-cell-engaging antibody AMG 330. Blood 2014, 123, 356-365. [CrossRef]

34. Friedrich, M.; Henn, A.; Raum, T.; Bajtus, M.; Matthes, K.; Hendrich, L.; Wahl, J.; Hoffmann, P.; Kischel, R.; Rattel, B.; et al. Preclinical characterization of AMG 330, a CD3/CD33-bispecific T-cell-engaging antibody with potential for treatment of acute myelogenous leukemia. Mol. Cancer Ther. 2014, 13, 1549-1557. [CrossRef] [PubMed]

35. Laszlo, G.S.; Gudgeon, C.J.; Harrington, K.H.; Dell'Aringa, J.; Newhall, K.J.; Means, G.D.; Sinclair, A.M.; Kischel, R.; Frankel, S.R.; Walter, R.B. Cellular determinants for preclinical activity of a novel CD33/CD3 bispecific T-cell engager (BiTE) antibody, AMG 330, against human AML. Blood 2014, 123, 554-561. [CrossRef] [PubMed]

36. Ravandi, F.; Walter, R.B.; Subklewe, M.; Buecklein, V.; Jongen-Lavrencic, M.; Paschka, P.; Ossenkoppele, G.J.; Kantarjian, H.M.; Hindoyan, A.; Agarwal, S.K.; et al. Updated results from phase I dose-escalation study of AMG 330, a bispecific T-cell engager molecule, in patients with relapsed/refractory acute myeloid leukemia (R/R AML). J. Clin. Oncol. 2020, 38, 7508. [CrossRef]

37. Subklewe, M.; Stein, A.; Walter, R.B.; Bhatia, R.; Wei, A.; Ritchie, D.; Dai, T.; Hindoyan, A.; Anderson, A.; Khaldoyanidiet, S.; et al. Updated Results from a Phase 1 First-in-Human Dose Escalation Study of AMG 673, a Novel aAnti-CD33/CD3 Bite ${ }^{\circledR}$ (Bispecific t-Cell Engager) in Patients with Relapsed/Refractory Acute Myeloid Leukemia; European Hematology Association: The Hague, The Netherlands, 2020.

38. Westervelt, P.; Cortes, J.E.; Altman, J.K.; Long, M.; Oehler, V.G.; Gojo, I.; Roboz, G.J.; Guenot, J.; Chun, P. Phase 1 First-in-Human Trial of AMV564, a Bivalent Bispecific (2:2) CD33/CD3 T-Cell Engager, in Patients with Relapsed/Refractory Acute Myeloid Leukemia (AML). Blood 2019, 137, 834. [CrossRef]

39. Vergez, F.; Green, A.S.; Tamburini, J.; Sarry, J.-E.; Gaillard, B.; Cornillet-Lefebvre, P.; Pannetier, M.; Neyret, A.; Chapuis, N.; Ifrah, N.; et al. High levels of CD34+CD38low / -CD123+ blasts are predictive of an adverse outcome in acute myeloid leuke-mia: A Groupe Ouest-Est des Leucémies Aiguës et Maladies du Sang (GOELAMS) study. Haematologica 2011, 96, 1792-1798. [CrossRef]

40. Uy, G.L.; Aldoss, I.; Foster, M.C.; Sayre, P.H.; Wieduwilt, M.J.; Advani, A.S.; Godwin, J.E.; Arellano, M.L.; Sweet, K.L.; Emadi, A.; et al. Flotetuzumab as salvage immunotherapy for refractory acute myeloid leukemia. Blood 2021, 137, 751-762. [CrossRef] [PubMed] 
41. Ravandi, F.; Bashey, A.; Stock, W.; Foran, J.M.; Mawad, R.; Egan, D.; Blum, W.; Yang, A.; Pastore, A.; Johnson, C.; et al. Complete Responses in Relapsed/Refractory Acute Myeloid Leukemia (AML) Patients on a Weekly Dosing Schedule of Vi-becotamab (XmAb14045), a CD123 x CD3 T Cell-Engaging Bispecific Antibody; Initial Results of a Phase 1 Study. Blood 2020, 136, 4-5. [CrossRef]

42. Uckun, F.M.; Lin, T.L.; Mims, A.S.; Patel, P.; Lee, C.; Shahidzadeh, A.; Shami, P.J.; Cull, E.; Cogle, C.R.; Watts, J. A Clinical Phase 1B Study of the CD3xCD123 Bispecific Antibody APVO436 in Patients with Relapsed/Refractory Acute Myeloid Leu-kemia or Myelodysplastic Syndrome. Cancers 2021, 13, 4113. [CrossRef]

43. Mascarenhas, J.; Cortes, J.; Huls, G.; Venditi, A.; Breems, D.; De Botton, S.; Deangelo, D.; van de Loosdrecht, A.; Jongen-Lavrencic, M.; Borthaku, G.; et al. Update from the Ongoing Phase I Multinational Study of MCLA-117, a Bispecific CLEC12a x CD3 T-Cell Engager, in Patients (pts) with Acute Myelogenous Leukemia (AML); European Hematology Association: The Hague, The Netherlands, 2020.

44. Berger, R.; Rotem-Yehudar, R.; Slama, G.; Landes, S.; Kneller, A.; Leiba, M.; Nagler, A.; Koren-Michowitz, M.; Shimoni, A. Phase I safety and pharmacokinetic study of CT-011, a humanized antibody interacting with PD-1, in patients with ad-vanced hematologic malig-nancies. Clin. Cancer Res. 2008, 14, 3044-3051. [CrossRef]

45. Héninger, E.; Krueger, T.E.G.; Lang, J.M.; Heninger, E. Augmenting Antitumor Immune Responses with Epigenetic Modify-ing Agents. Front. Immunol. 2015, 6, 29. [CrossRef]

46. Yang, H.; Bueso-Ramos, C.; Dinardo, C.; Estecio, M.R.; Davanlou, M.; Geng, Q.-R.; Fang, Z.; Nguyen, M.; Pierce, S.; Wei, Y.; et al. Expression of PD-L1, PD-L2, PD-1 and CTLA4 in myelodysplastic syndromes is enhanced by treatment with hypo-methylating agents. Leukemia 2014, 28, 1280-1288. [CrossRef]

47. Daver, N.; Boddu, P.; Garcia-Manero, G.; Yadav, S.S.; Sharma, P.; Allison, J.; Kantarjian, H. Hypomethylating agents in combination with immune checkpoint inhibitors in acute myeloid leukemia and myelodysplastic syndromes. Leukemia 2018, 32, 1094-1105. [CrossRef] [PubMed]

48. Saxena, K.; Herbrich, S.M.; Pemmaraju, N.; Kadia, T.M.; DiNardo, C.D.; Borthakur, G.; Pierce, S.A.; Jabbour, E.; Wang, S.A.; Bueso-Ramos, C.; et al. A phase 1b/2 study of azacitidine with PD-L1 antibody avelumab in relapsed/refractory acute myeloid leukemia. Cancer 2021, 127, 3761-3771.

49. Daver, N.; Garcia-Manero, G.; Basu, S.; Boddu, P.C.; Alfayez, M.; Cortes, J.E.; Konopleva, M.; Ravandi-Kashani, F.; Jabbour, E.; Kadia, T.M.; et al. Efficacy, Safety, and Biomarkers of Response to Azacitidine and Nivolumab in Relapsed/Refractory Acute Myeloid Leukemia: A Nonrandomized, Open-Label, Phase II Study. Cancer Discov. 2018, 9, 370-383. [CrossRef] [PubMed]

50. Daver, N.G.; Garcia-Manero, G.; Konopleva, M.Y.; Alfayez, M.; Pemmaraju, N.; Kadia, T.M.; Dinardo, C.D.; Cortes, J.E.; Ravandi, F.; Abbas, H.; et al. Azacitidine (AZA) with Nivolumab (Nivo), and AZA with Nivo + Ipilimumab (Ipi) in Re-lapsed/Refractory Acute Myeloid Leukemia: A Non-Randomized, Prospective, Phase 2 Study. Blood 2019, 134, 830. [CrossRef]

51. Lindblad, K.E.; Thompson, J.; Gui, G.; Valdez, J.; Worthy, T.; Tekleab, H.; Hourigan, C.S.; Hughes, T.; Goswami, M.; Oetjen, K.; et al. Pembrolizumab and Decitabine for Re-fractory or Relapsed Acute Myeloid Leukemia. Blood 2018, 132, 1437. [CrossRef]

52. Davids, M.S.; Kim, H.T.; Bachireddy, P.; Costello, C.; Liguori, R.; Savell, A.; Lukez, A.P.; Avigan, D.; Chen, Y.B.; McSweeney, P.; et al. Ipilimumab for Patients with Relapse after Allogeneic Transplantation. N. Engl. J. Med. 2016, 375, 143-153.

53. Brunner, A.M.; Esteve, J.; Porkka, K.; Knapper, S.; Vey, N.; Scholl, S.; Garcia-Manero, G.; Wermke, M.; Janssen, J.; Traer, E.; et al Efficacy and Safety of Sabatolimab (MBG453) in Combination with Hypomethylating Agents (HMAs) in Patients with Acute Myeloid Leukemia (AML) and High-Risk Myelodysplastic Syndrome (HR-MDS): Updated Results from a Phase 1b Study. Blood 2020, 136, 657. [CrossRef]

54. Daver, N.; Al Malki, M.; Asch, A.; Lee, D.; Kambhampati, S.; Donnellan, W.; Marcucci, G.; Vyas, P.; Lin, M.; Chao, M.; et al. The first-in-class ANTI-CD47 antibody magrolimab combined with azacitidine is well-tolerated and effective in AML pa-tients: Phase 1B results. Blood 2019, 134, 569.

55. Garcia-Manero, G.; Daver, N.G.; Xu, J.; Chao, M.; Chung, T.; Tan, A.; Wang, V.; Wei, A.; Vyas, P.; Sallman, D.A Magro-limab + azacitidine versus azacitidine + placebo in untreated higher risk (HR) myelodysplastic syndrome (MDS): The phase 3, randomized, ENHANCE study. J. Clin. Oncol. 2021, 39, TPS7055. [CrossRef]

56. Fiorenza, S.; Turtle, C.J. CAR T Cell Therapy for Acute Myeloid Leukemia: Preclinical Rationale, Current Clinical Progress, and Barriers to Success. BioDrugs 2021, 35, 281-302. [CrossRef]

57. Liu, L.; Cao, Y.; Pinz, K.; Ma, Y.; Wada, M.; Chen, K.; Ma, G.; Shen, J.; Tse, C.O.; Su, Y.; et al. First-in-human CLL1-CD33 compound car (CCAR) T cell therapy in relapsed and refractory acute myeloid leukemia. Blood 2018, 132, 901. [CrossRef]

58. Qin, H.; Yang, L.; Chukinas, A.J.; Shah, N.N.; Tarun, S.; Pouzolles, M.; Chien, C.D.; Niswander, L.M.; Welch, A.R.; Taylor, A.N.; et al. Systematic preclinical evaluation of CD33-directed chimeric antigen receptor T cell immunotherapy for acute my-eloid leukemia defines optimized construct design. J. Immunother. Cancer 2021, 9, e003149. [CrossRef]

59. Cui, Q.; Qian, C.; Xu, N.; Kang, L.; Dai, H.; Cui, W.; Song, B.; Yin, J.; Li, Z.; Zhu, X.; et al. CD38-directed CAR-T cell therapy: A novel immunotherapy strategy for relapsed acute myeloid leukemia after allogeneic hematopoietic stem cell transplanta-tion. J. Hematol. Oncol. 2021, 14, 82. [CrossRef] [PubMed]

60. Meyer, J.E.; Loff, S.; Dietrich, J.; Spehr, J.; Jurado Jiménez, G.; von Bonin, M.; Ehninger, G.; Cartellieri, M.; Ehninger, A. Evaluation of switch-mediated cost-imulation in trans on universal CAR-T cells (UniCAR) targeting CD123-positive AML. Oncoimmunology 2021, 10, 1945804. [CrossRef] 
61. Loff, S.; Dietrich, J.; Meyer, J.-E.; Riewaldt, J.; Spehr, J.; von Bonin, M.; Gründer, C.; Swayampakula, M.; Franke, K.; Feldmann, A.; et al. Rapidly Switchable Universal CAR-T Cells for Treatment of CD123-Positive Leukemia. Mol. Ther. Oncolytics 2020, 17, 408-420. [CrossRef] [PubMed]

62. Wermke, M.; Kraus, S.; Ehninger, A.; Bargou, R.C.; Goebeler, M.-E.; Middeke, J.M.; Cartellieri, M.; Kreissig, C.; Von Bonin, M.; Pehl, M.; et al. Proof of concept for a rapidly switchable universal CAR-T platform with UniCAR-T-CD123 in re-lapsed/refractory AML. Blood 2021, 137, 3145-3148. [CrossRef]

63. Bachier, C.; Borthakur, G.; Hosing, C.; Blum, W.; Rotta, M.; Ojeras, P.; Nikiforow, S.; Barnett, B.; Rajangam, K.; Majhail, N.S. A phase 1 study of NKX101, an allogeneic car natural killer (NK) cell therapy, in subjects with relapsed/refractory (r/r) acute myeloid leukemia (AML) or higher risk myelodysplastic syndrome (MDS). Blood 2020, 136, 42-43. [CrossRef]

64. Van de Loosdrecht, A.A.; van Wetering, S.; Santegoets, S.J.; Singh, S.K.; Eeltink, C.M.; den Hartog, Y.; de Gruijl, T.D.; Koppes, M.; Kaspers, J.; Ossenkoppele, G.J.; et al. A novel allogeneic off-the-shelf dendritic cell vaccine for post-remission treatment of elderly patients with acute myeloid leukemia. Cancer Immunol. Immunother. 2018, 67, 1505-1518. [CrossRef] [PubMed] 